\title{
Positive effects of robotic exoskeleton training of upper limb reaching movements after stroke
}

\author{
Antonio Frisoli ${ }^{1 *}$, Caterina Procopio ${ }^{1,2}$, Carmelo Chisari ${ }^{2}$, llaria Creatini ${ }^{2}$, Luca Bonfiglio ${ }^{2}$, Massimo Bergamasco ${ }^{1}$, \\ Bruno Rossi ${ }^{2}$ and Maria Chiara Carboncini ${ }^{2}$
}

\begin{abstract}
This study, conducted in a group of nine chronic patients with right-side hemiparesis after stroke, investigated the effects of a robotic-assisted rehabilitation training with an upper limb robotic exoskeleton for the restoration of motor function in spatial reaching movements. The robotic assisted rehabilitation training was administered for a period of 6 weeks including reaching and spatial antigravity movements. To assess the carry-over of the observed improvements in movement during training into improved function, a kinesiologic assessment of the effects of the training was performed by means of motion and dynamic electromyographic analysis of reaching movements performed before and after training. The same kinesiologic measurements were performed in a healthy control group of seven volunteers, to determine a benchmark for the experimental observations in the patients' group. Moreover degree of functional impairment at the enrolment and discharge was measured by clinical evaluation with upper limb Fugl-Meyer Assessment scale (FMA, 0-66 points), Modified Ashworth scale (MA, 0-60 pts) and active ranges of motion. The robot aided training induced, independently by time of stroke, statistical significant improvements of kinesiologic (movement time, smoothness of motion) and clinical (4.6 \pm 4.2 increase in FMA, $3.2 \pm 2.1$ decrease in MA) parameters, as a result of the increased active ranges of motion and improved cocontraction index for shoulder extension/flexion. Kinesiologic parameters correlated significantly with clinical assessment values, and their changes after the training were affected by the direction of motion (inward vs. outward movement) and position of target to be reached (ipsilateral, central and contralateral peripersonal space). These changes can be explained as a result of the motor recovery induced by the robotic training, in terms of regained ability to execute single joint movements and of improved interjoint coordination of elbow and shoulder joints.
\end{abstract}

Keywords: Upper extremity hemiparesis, Stroke, Robot-aided rehabilitation, Motor synergies

\section{Background}

Impairment of upper limb function is one of the most common sequelae following stroke; in particular arm function is found to be altered in $73 \%$ to $88 \%$ of first time stroke survivors (infarctions only), and 55\% to $75 \%$ still experience problems that impair their activities of daily living for up to 3 to 6 months or more [1,2].

Impairments limit the patient's autonomy in daily living and may lead to permanent disability [3]. The deficits are typically characterized by weakness of specific muscles [4], lack of mobility between structures at the shoulder girdle

\footnotetext{
* Correspondence: a.frisoli@sssup.it

'PERCRO (Perceptual Robotics) Laboratory, Scuola Superiore Sant'Anna, Viale Rinaldo Piaggio, 34, 56025Pontedera, Pisa, Italy

Full list of author information is available at the end of the article
}

[5], incorrect timing of components within a movement pattern [6,7] and loss of interjoint coordination [8]. Consequently goal directed movements in hemiplegic patients are characterized by lower movement amplitude, prolonged movement time, segmented trajectories and abnormal pattern of muscle activation. Compensatory motor strategies, characterized by adaptations to muscle imbalance [9], are commonly adopted by stroke patients in attempt to overcome these impairments.

Various rehabilitation interventions to improve skill reacquisition have shown promising results in overcoming motor impairment after stroke [10].

High intensity and task specific upper limb treatment consisting of active, highly repetitive movement is one of the most effective approaches to arm function post-

\section{Biomed Central}


stroke restoration [11-13]. Recent studies moreover suggest that given appropriate training, motor improvements of the upper limb can continue well into the chronic stage of stroke [14-16].

The use of robot devices in rehabilitation can provide high intensity, repetitive, task specific and interactive treatment of the impaired upper limb and an objective, reliable mean of monitoring patients progress. Systematic review confirms the potential for robotic assisted devices to elicit improvements in upper limb function $[17,18]$. Moreover virtual reality provided a unique medium where therapy can be provided within a functional, purposeful and motivating context and can be readily graded and documented [19]. The cortical reorganization and associated functional motor recovery after virtual reality in patient with chronic stroke are documented also by fMRI [20].

While several studies have already investigated the effects of robot assisted training in planar movements performed in the horizontal plane [21], the effect of training on the control and production of multi-joint and spatial functional arm movements, including movements against gravity, in hemiparetic subjects has received less attention.

It has been already shown that stereotyped movement patterns [8] due to abnormal muscle co-activation result in a reduced active range of motion against gravity. In particular providing antigravity limb support, leads to a reduction of the abnormal coupling between shoulder abduction/elbow flexion [22] and promising results have been found in the robotic training of patients with antigravity vertical movements that involve shoulder elevation [23]. Moreover orthoses providing only passive gravity assistance to the arm in reaching movements can induce comparable clinical improvements to those obtained with robotic training [24].

In this study we have investigated the effects of robot aided training on the recovery of spatial reaching movements, with a focus on point-to-point reaching movements performed in different directions, analysing how muscle imbalance in stroke influences the process of motor recovery in terms of regain of smooth movement, interjoint coordination and agonistic/antagonistic muscle recruitment.

A robotic treatment was administered through the LEXOS [25,26], a robotic exoskeleton for the upper limb, in a group of nine patients with chronic hemiparetic stroke. Exoskeleton robotic systems allow to execute full spatial multi-joint functional arm movements, including elevation movements with shoulder abduction, providing either variable gravity support or active assistance to the impaired arm [27].

To assess the carry-over of the observed improvements in movement during training into improved function, changes in movement execution and smoothness of motion were analysed through a kinesiologic assessment, consisting in the motion and dynamic electromyographic analysis of reaching movements performed before and after training.

The kinesiologic performance (movement time, smoothness of motion) was then analysed in relation to the changes in the EMG pattern of agonist-antagonist muscle co-activation and shoulder-elbow interjoint coordination.

\section{Methods \\ Participants}

Nine right hemiparetic subjects (aged 61.4 \pm 14.1 years) participated to the study. They had sustained a single left stroke between 3 and 9 years previously, leading to right-side hemiparesis. All subjects were able to understand simple commands and to perform a reaching movement with the affected arm. They had no other neurological, neuromuscular or orthopaedic disorders and no visual deficit. Explicit exclusion criteria were perceptual, apraxic or major cognitive deficits, shoulder sub-luxation or pain in the upper limb, spasticity (single muscle Modified Ashworth Scale Score >2). In addition, subjects were excluded if they had occipital, cerebellar or brainstem lesions. Clinical and demographic data with baseline clinical assessment at the enrolment are reported in Table 1.

The study was approved by the local ethical committee; subjects were informed of the procedure and gave their informed consent to participate to the study.

Both prior to and after the robotic training, the subjects were tested clinically for upper limb motor function by the upper limb Fugl-Meyer (FMA) scale (0-66 points) [28], muscle spasticity by the Modified Ashworth (MA) scale rating stiffness in 15 different muscle groups of the upper limb (0-60 points) [29] and in terms of active Ranges of Motion. Ranges of motion, both active and passive, were measured by means of a long-arm goniometer with a $360^{\circ}$ scale marked in one degree increments.

\section{Kinesiologic assessment}

The subjects were also submitted, before and after robotic training, to a kinesiologic test of selected movements. Free arm reaching and grasp of an object positioned on a horizontal plane were recorded by means of an integrated motion capture system and surface EMG recording system (Elite-BTS) composed of an 8 channel electromyography system and 6 cameras, with $100 \mathrm{~Hz}$ acquisition frequency and a position accuracy of $1.5 \mathrm{~mm}$ in the adopted configuration.

Motion capture was made with 4 surface markers of $0.5 \mathrm{~cm}$ diameter, covered with reflective material; placed at four points (sternum-clavicle junction, shoulder, elbow, wrist). 
Table 1 Demographic data and clinical scores for hemiparetic subjects

\begin{tabular}{|c|c|c|c|c|c|c|}
\hline Pt. & Sex & Age & Type of stroke & Site of stroke & $\begin{array}{l}\text { Fugl-Meyer } \\
\text { score (66) }\end{array}$ & $\begin{array}{l}\text { Ashworth } \\
\text { score }(60)\end{array}$ \\
\hline 1 & M & 79 & Haemorrhagic & $\begin{array}{l}\text { posterior portion of the left lateral } \\
\text { ventricle roof with an extension } \\
\text { corresponding to the semi oval } \\
\text { centre }\end{array}$ & 36 & 19,5 \\
\hline 2 & M & 72 & Haemorrhagic & $\begin{array}{l}\text { temporo-parietal, cortical- subcortical } \\
\text { left side }\end{array}$ & 52 & 11 \\
\hline 3 & M & 68 & Ischemic & $\begin{array}{l}\text { parieto-occipital, cortical-subcortical } \\
\text { left side }\end{array}$ & 12 & 10,5 \\
\hline 4 & M & 69 & Ischemic & $\begin{array}{c}\text { extensive lesion in the left parietal } \\
\text { side }\end{array}$ & 56 & 5 \\
\hline 5 & M & 58 & Haemorrhagic & $\begin{array}{c}\text { intra-parenchymal lenticular-capsular } \\
\text { left collection }\end{array}$ & 57 & 4,5 \\
\hline 6 & $\mathrm{~F}$ & 42 & Haemorrhagic & midbrain-thalamus left lesion & 12 & 12 \\
\hline 7 & M & 58 & Haemorrhagic & temporo-parietal left side & 43 & 7,5 \\
\hline 8 & M & 37 & Haemorrhagic & nucleo-capsule-radiata left side & 37 & 8,5 \\
\hline 9 & M & 70 & Haemorrhagic & temporo-parietal left side & 17 & 7,5 \\
\hline
\end{tabular}

EMG signals were acquired from four muscle groups, respectively the couple of agonists/antagonists involved in elbow flexion/extension, triceps brachii (TB) and biceps brachii (BB), and in shoulder extension/flexion, anterior deltoid (AD) and posterior deltoid (PD). The activity was obtained using standard $\mathrm{Ag} / \mathrm{AgCl}$ bipolar surface electrodes $(10 \mathrm{~mm}$ diameter $)$. Electrodes were positioned over the border of the distal third of the muscle halfway between the innervations zone and the distal tendon parallel to the muscle fibres according to SENIAM guidelines [30].

Each patient was asked to sit at a table on which a target to be reached was placed at about $30 \mathrm{~cm}$ distance from the subject; at the beginning patients had the right upper limb approximately 90 degrees flexed in the transverse plane, than they were invited to perform the extension of the arm (outward movement) to bring the limb to the target, to extend the palm to reach the target and, at the end, to bring back the limb at the initial position (inward movement). The patients were asked to operate at their own preferred speed to reach 3 different positions on the transverse plane (in contralateral, in central and in ipsilateral positions, according to [31]), as shown in Figure 1, and to repeat the same movement 3 times for each target position.

Seven volunteers (aged 47.14 \pm 16.55 years), righthanded, were enrolled as well in a healthy control group. They were asked to perform the same kinesiologic procedures, to acquire a baseline of motion data to be used as a benchmark for the patients' group.

\section{Robotic training}

The training session consisted of repetitive, goal directed forward reaching movements actively performed by the subject (partially assisted by the robotic device). In accordance to previous studies [21], robot aided therapy consisted of 3 one-hour rehabilitation sessions per week for a total of 6 weeks (i.e., 18 therapy sessions). Training was conducted by means of the L-Exos (see Figure 2, [25]), an active robotic exoskeleton, that can provide either active guidance during the execution of some exercise or gravity support for the weight arm. The exoskeleton has four actuated Degrees of Freedom (DoFs) with anthropomorphic kinematics, so that active assistance can be provided for shoulder abduction/adduction, flexion-extension, internal/external rotation and

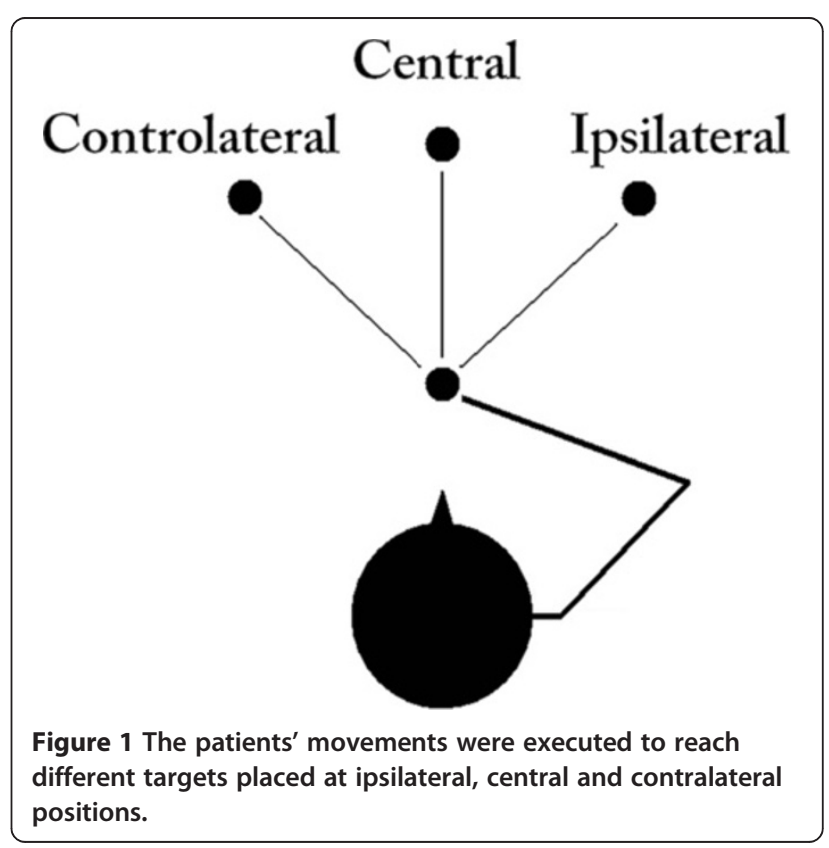




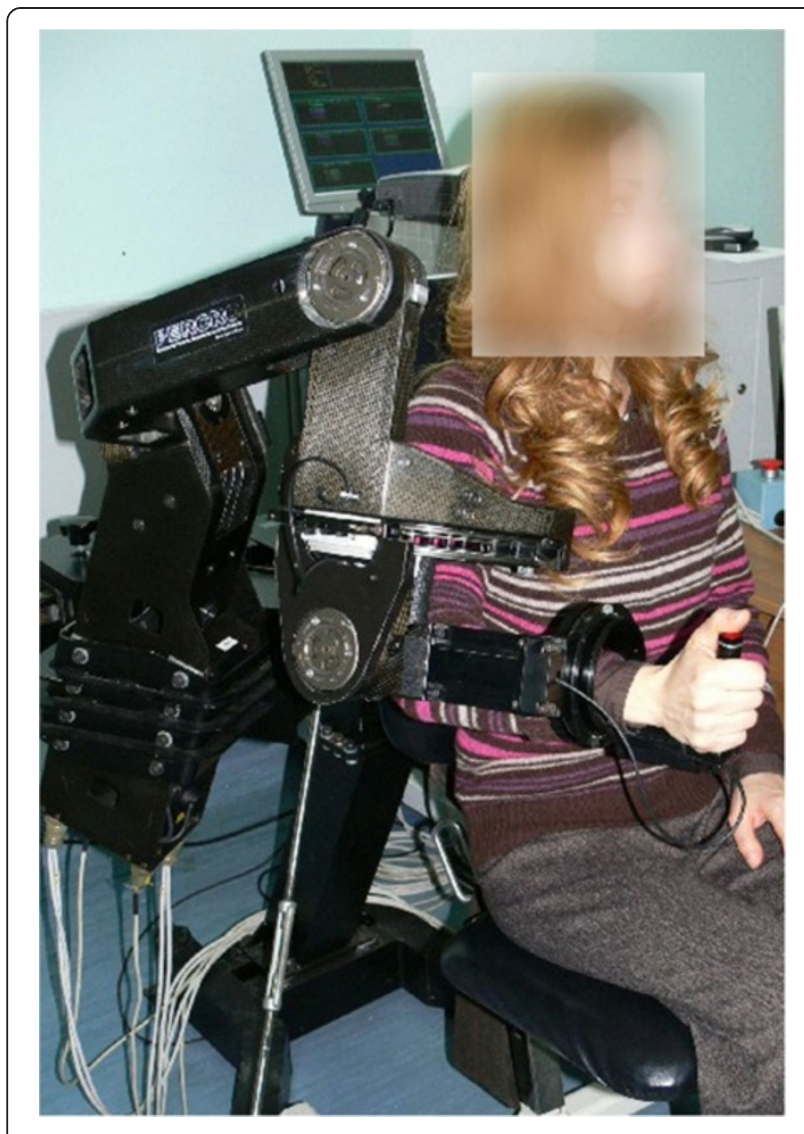

Figure 2 The L-Exos robotic exoskeleton. for elbow extension/flexion, and one passive DoF, corresponding to the wrist prono-supination.

During the training sessions the patients were sat down on a seat, with their right forearm wearing the exoskeleton and a video projector displaying frontally the virtual scenario (see Figure 3, panel A).

Each rehabilitation session consisted of three different virtual reality mediated exercises [32].

In the first exercise, different fixed virtual targets were displayed to the patient as grey spheres disposed on a horizontal row, (Figure 3, panel B). When one of the fixed targets was activated, the patients were instructed to reach it, by actively following the position of a yellow sphere moving automatically towards the target with a motion generated along a straight trajectory according to a minimum jerk model [33]. The patients were actively aided by the robot, providing an impedance-based assistance proportional to the position error between the yellow sphere and patient hand's position. Speed of the task was adjustable among three different values $(5 \mathrm{~cm} /$ $\mathrm{s}, 10 \mathrm{~cm} / \mathrm{s}$ and $15 \mathrm{~cm} / \mathrm{s}$ ), as well as the position of the targets to be reached, in terms of height and depth. Each patient performed training exercises at two different speeds. Speed of target, position of virtual targets (height, depth) were decided during a trial session at the enrolment, on the basis of the outcomes of the clinical evaluation, by adjusting the difficulty of the exercise to the capabilities of each patient.

In the second exercise (Figure 3, panel C) the patients were asked to draw a circular trajectory in a virtual plane, in the two conditions with and without the robot impedance-based assistance, providing a constraint along the requested trajectory. The task required an active interjoint coordination of elbow and shoulder joints to generate circular trajectories. In both conditions no active driving force was applied to the patients' limb, but only support for gravity compensation until the patients were able to autonomously perform the task.

In the third exercise (Figure 3, Panel D) the patients were asked to assemble nine cubes in a virtual puzzle. Collisions with and between the cubes were simulated as computed contact forces applied at the patient's hand by the robot. Two facilitation strategies were provided through the robot to perform the task: amplification of movement by an adjustable gain between the distance covered by the arm and the associated movement generated in the simulation, and active compensation of the arm's weight, as in the second exercise. The levels of adjustable gain and active compensation were decided during a trial session at the enrolment according to the motor impairment of each patient, in order to make each patient able to autonomously complete the requested exercises.

\section{Data analysis}

Kinesiologic individual data collected before and after training period in free arm motion were filtered with a smoothing low-pass filter to eliminate components above $200 \mathrm{~Hz}$. Velocity was computed from position data with a central finite difference method over 22 subintervals.

Two main Performance Indexes (PI) were computed based on kinesiologic assessment of arm movement, analysing execution time (PI1) and smoothness (PI2) of the movement. The smoothness and regularity of the arm movement was measured by counting the number of local minima in the wrist velocity profile (PI2). Both indexes were then correlated to clinical scale assessment (FMA and MA scores).

Moreover the same indexes were recomputed on the outward and inward segments of the whole trajectory, obtained by automatic segmentation according to the following procedures.

The reaching movements, measured as displacement of the wrist, was segmented into three phases (outward movement, achievement of target, inward movement) on the basis of the displacement and speed profiles. The start of the outward phase was identified as the 
reference instant when a quarter of the maximum speed was achieved in each repetition, while the starting instant of the inward phase was identified at a quarter of the negative peak of the maximum negative speed.

Then times of the outward (PI1a) and inward (PI1b) movements were computed, and number of minima in the velocity profiles associated to the same phases (PI2a, PI2b). Figure 4 shows an example of automatic extraction of duration of outward and inward phase (continuous line in grey), while on the same plot the count of local minima in the velocity profile is shown.

Joint angles variations for shoulder and elbow were computed respectively as the angle between the segments sternum-shoulder-elbow and shoulder-elbowwrist.

Interjoint coordination was assessed by considering only the outward phase of the reaching movement, obtained by the same automatic segmentation algorithm presented above, and computing the diagrams of shoulder vs. elbow angle variations. For reaching tasks towards contralateral and central targets, since a coordinated rotation of shoulder and elbow joints acting in synergy is required, the interjoint coordination was evaluated computing the linear correlation coefficient between each pair of shoulder and elbow angles associated to movement execution. For reaching tasks towards ipsilateral targets, since the same movement can be executed with single joint movements of either shoulder or elbow joints, according to the motion strategy adopted by each subject, an index of coordination was computed as the ratio of maximum elbow $\left(\Delta \alpha_{E L B}\right)$ to shoulder $\left(\Delta \alpha_{S H}\right)$ excursion, according to the formula $\frac{\max \left(\Delta \alpha_{E L B}\right)}{\max \left(\Delta \alpha_{S H}\right)}$. $\max \left(\Delta \alpha_{S H}\right)$.

All EMG signals were band-pass filtered (30-1.000 Hz). The co-contraction index $(\mathrm{CCI})$ of activation of agonistic/ antagonistic muscles for the couples $\mathrm{TB} / \mathrm{BB}$ and $\mathrm{AD} / \mathrm{PD}$ were then calculated to provide a normalized score evaluating co-contraction before and after the training period. The co-contraction index was computed only in the time window corresponding to the acceleration peak, ranging from the onset of movement $\left(t_{1}\right)$ as defined before up to half of the velocity peak $\left(t_{2}\right)$ (see Figure 5 ), as the ratio of the root mean square (RMS) of the EMG signals of agonist and antagonist muscles [34], according to the formula:

$$
\mathrm{CCI}(\mathrm{ag} / \mathrm{ant})=\frac{\mathrm{EMG}_{a g, R M S}}{\mathrm{EMG}_{a n t, R M S}}=\frac{\sqrt{\int_{t_{1}}^{t_{2}}\left[\mathrm{EMG}_{a g}\right]^{2} d t}}{\sqrt{\int_{t_{1}}^{t_{2}}\left[\mathrm{EMG}_{a n t}\right]^{2} d t}}
$$

The kinematic reference used for the computation of the time window [t1-t2] was chosen as the ulna displacement for the CII1 of AD-PD muscles and as the elbow angle for the CII2 of TB/BB muscles, as shown in the example reported in Figure 5. In Figure 5, right side, it is possible to see how the antigravity action required to the biceps to sustain the weight of the forearm during all the movement, induces an associated co-activation of the triceps.

To make the scores more intuitively interpretable so that a high score reflected more normal function, the ratio of agonist/antagonist was used in preference to the ratio of antagonist/agonist, as by previous studies [34].

Statistical analysis was conducted with parametric tests. Two-sided $t$-test for paired samples was used to assess if changes in scores from admission to discharge were statistically significant in the patients' group, linear regression analysis and Pearson correlation coefficients were used for the analysis of correlation among data. Post-hoc Tukey HSD test was used to compare the healthy control group with the patient's group.

\section{Results}

\section{Clinical and kinematic assessment}

We observed a significant improvement in FMA from $35.8 \pm 18.2$ before training to $40.3 \pm 17.6$ after training $(\mathrm{t}$ $(8)=3.3, p=0.006)$ and a reduction in MA scale from $9.6 \pm 4.5$ to $6.3 \pm 5.0(\mathrm{t}(8)=4.5, \mathrm{p}=0.001)$.

Significant improvements were found statistically associated to the execution of active movements. In particular we observed an increase of active range of motion for both shoulder and elbow joints, as reported in Table 2.

\section{Spatial-temporal assessment of movement}

In Figure 6, the average profile of ulna with associated speed are reported for one patient before and after training, during the execution of 3 reaching movements. The characteristic double peak profile in speed is clearly visible, as well as the increase of smoothness of movement after robotic training. Local minima in the speed profile can account for the smoothness of movement.

Table 3 reports changes obtained in performance indexes PI1 and PI2 and in co-contraction ratio CII1 for $\mathrm{AD} / \mathrm{PD}$ and $\mathrm{CII} 2$ for TB/BB. As a benchmark, the kinematic parameters observed in the healthy control group are reported in the last column of Table 3.

Both performance time and smoothness decreased in all conditions, with higher changes after training for ipsilateral and central targets than contralateral ones, as it is clearly visible in the graphical representation in Figure 7. Comparable performance values were reached for PI1 and PI2 at discharge in all target conditions.

Both parameters PI1 and PI2 were found to be significantly correlated with clinical assessment scores obtained with FMA and MA scales. In Table 4 we report the correlation values for PI1 and PI2 computed in the 

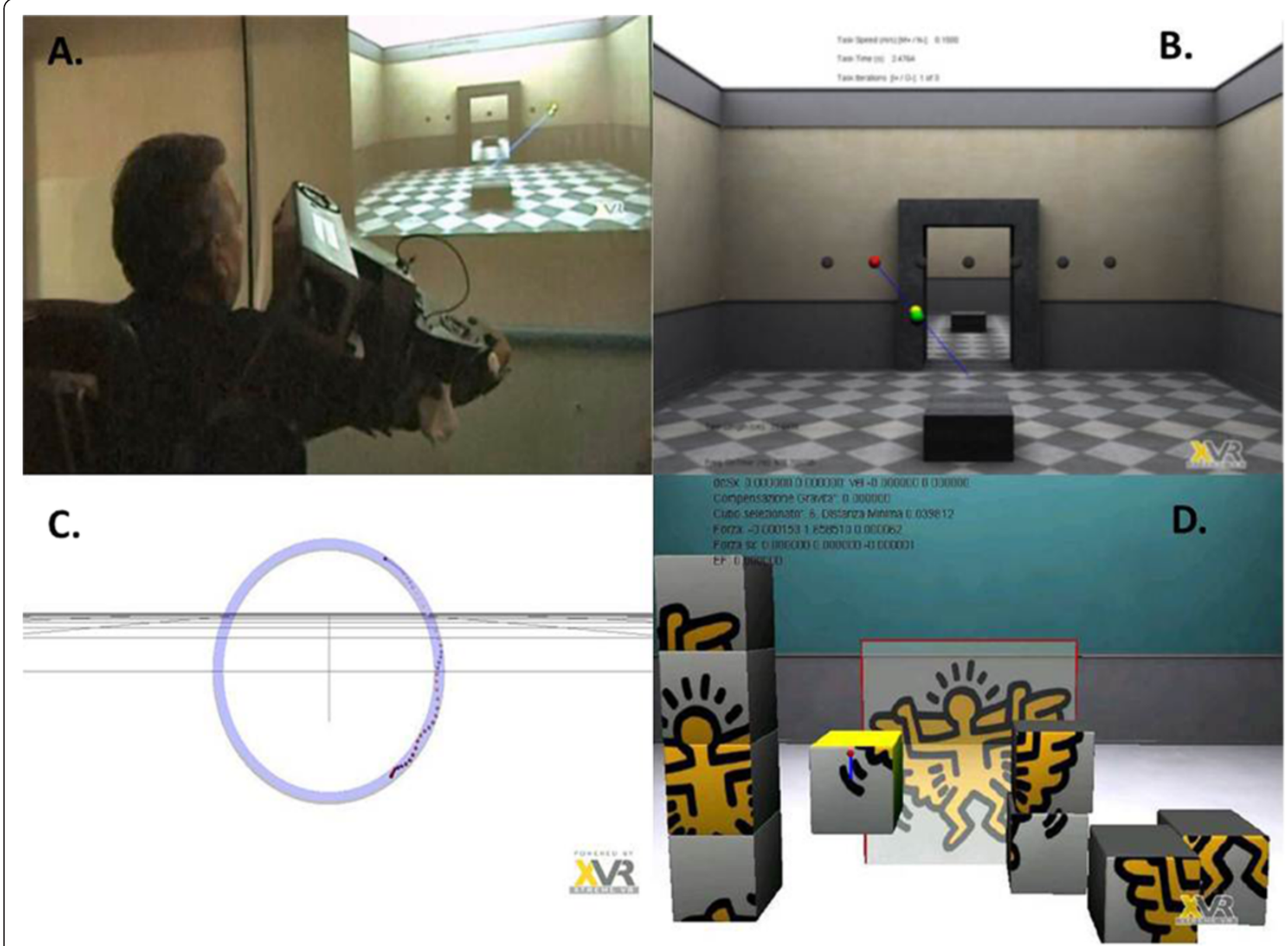

Figure 3 Panel A: one patient performing the robotic-aided therapy exercises in front of the VR scenario. Panels B,C,D: The virtual scenarios used for the training.

reaching movement towards a central target. In particular the fluctuations in velocity profile (PI2) during reaching presented the strongest correlation with clinical assessment, as graphically reported in Figure 8.

Considering the recruitment of muscle groups in the execution of movement, as shown in Figure 9, only significant changes of the co-contraction index CCI1 (AD/PD) associated to movement of shoulder extension/flexion were found, in all conditions, while no significant difference was found for the co- contraction index CII2 (TB/ BB) associated to elbow flexion/extension. No significant correlation was observed of the co-contraction indexes with clinical assessment scores from FMA and MA.

This is coherent with the proposed exercises requiring limited involvement of elbow joint, and a strong involvement of shoulder flexion/extension to move the hand forward and backward. The respective baseline measured in the healthy control group for the co-contraction index is reported as well in Figure 9. It is possible to see that there

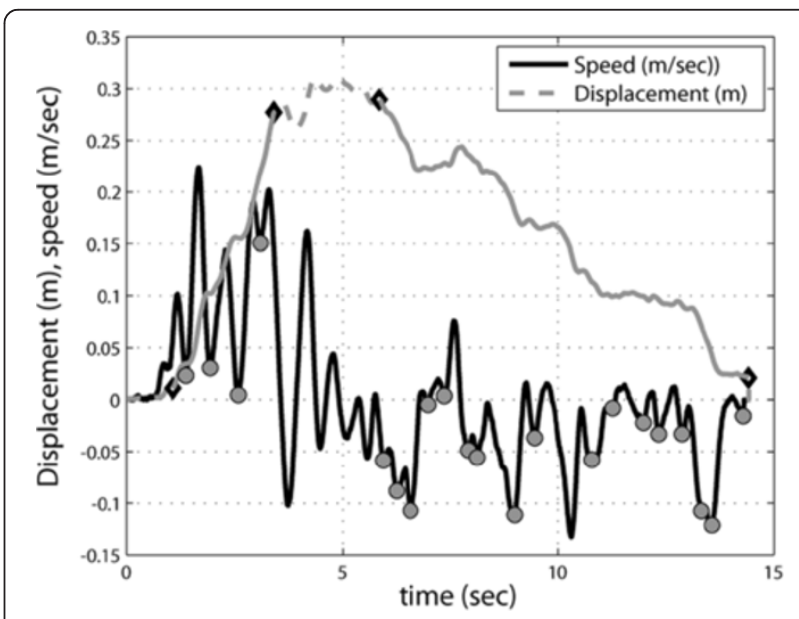

Figure 4 Example of automatic identification of kinematic features associated to the ulna displacement. 


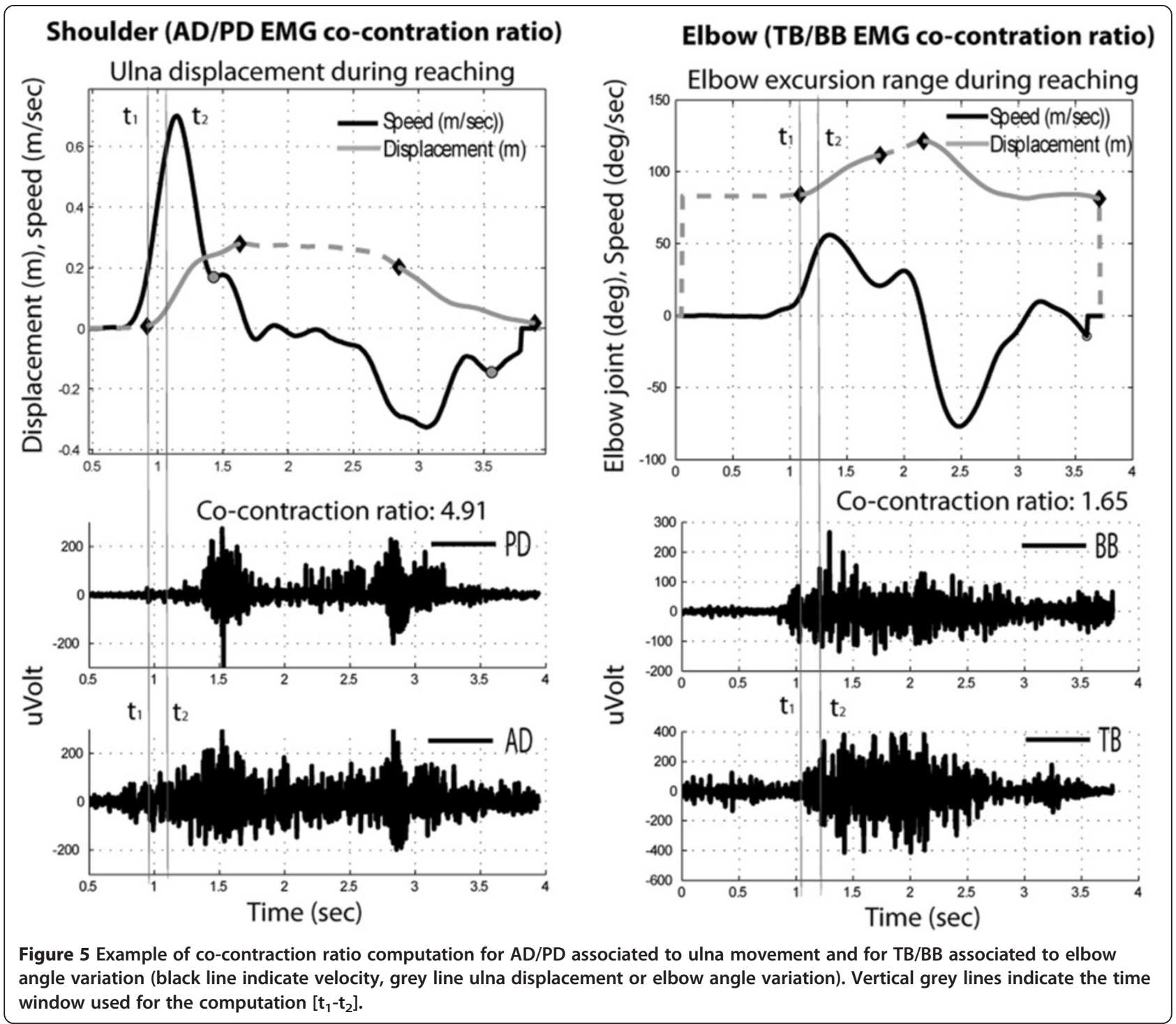

is a statistically significant difference among the two groups (patients vs. healthy control groups), and in particular that the CCI1 $(\mathrm{AD} / \mathrm{PD})$ is higher in the control group. For the CII2 $(\mathrm{TB} / \mathrm{BB})$ the prevalent action of the antagonist $(\mathrm{BB})$ during the outward phase observed in the control group is due to the antigravity action required to sustain the forearm, that leads to an associated co-activation of the triceps in the patients' group.

Table 2 Active range of motion changes after treatment $\left(* \mathbf{p}<0.05,{ }^{* *} \mathbf{p}<0.01\right.$ )

\begin{tabular}{lllll}
\hline & & Admission $(\mathbf{d e g})$ & Discharge (deg) & $\mathbf{p}$ \\
\hline Shoulder & Abduction* & $105 \pm 61.4$ & $112.2 \pm 56.3$ & 0.021 \\
& Flexion & $97.8 \pm 76.7$ & $108.3 \pm 69.6$ & 0.198 \\
& Extension** & $40 \pm 22.8$ & $52.8 \pm 15.4$ & 0.008 \\
& Internal Rotation & $56.7 \pm 34.2$ & $58.3 \pm 35$ & 0.438 \\
& External Rotation** & $54.4 \pm 25.5$ & $66.7 \pm 21.4$ & 0.008 \\
Elbow & Flexion* & $123.3 \pm 21.2$ & $130.6 \pm 14.5$ & 0.038 \\
& Extension* & $13.1 \pm 12.1$ & $6.7 \pm 10$ & 0.018 \\
\hline
\end{tabular}




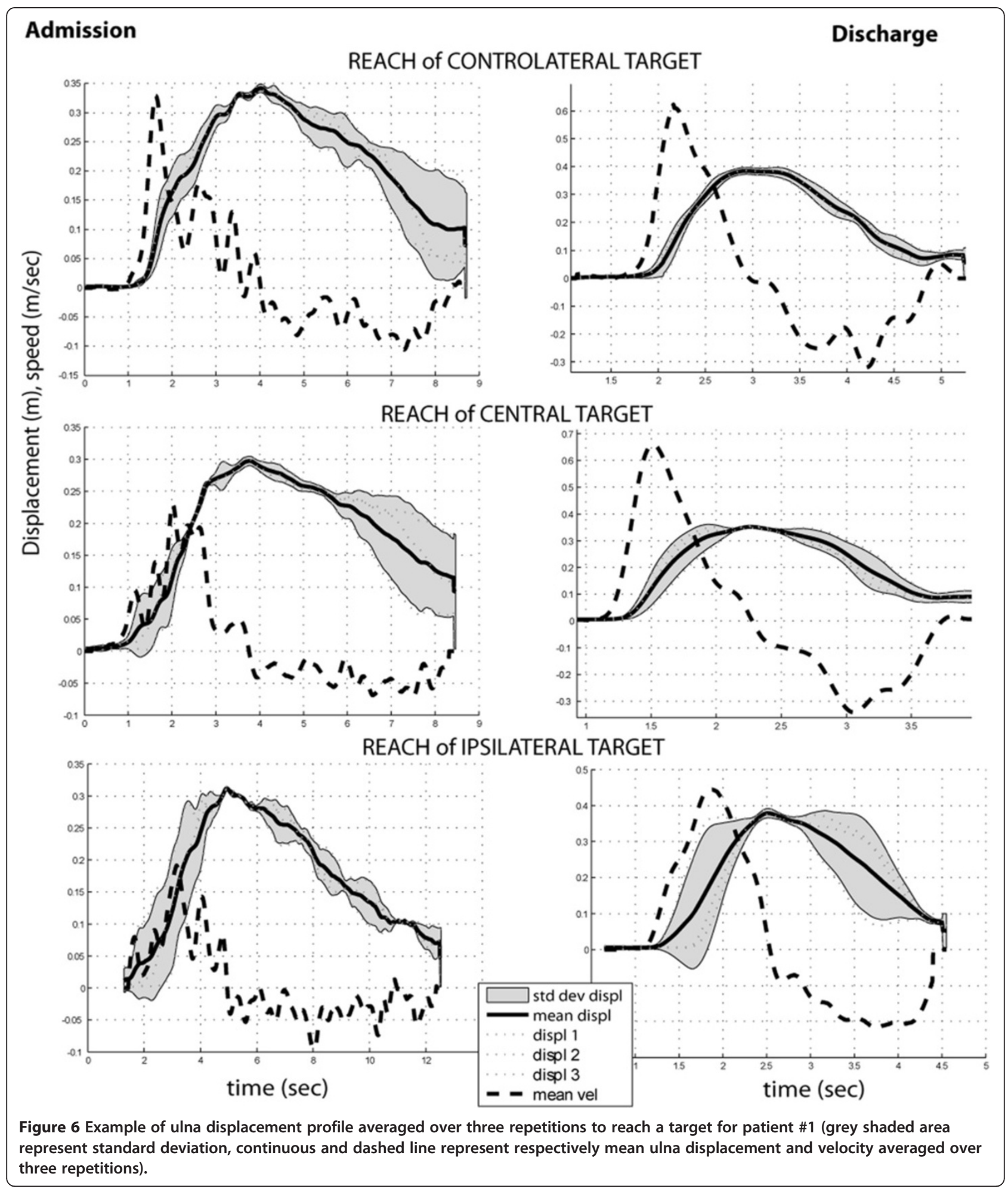

Outward vs. inward movement

The analysis of movement time and smoothness on the segmented inward and outward phases is reported in Table 5. It is possible to notice how a statistically significant change in performance is always reached for ipsilateral targets, while for central targets performance is unchanged for inward time and smoothness, and for contralateral targets only the inward smoothness is improved at discharge. 
Table 3 Mean values \pm standard deviation of performance indexes $(* \mathbf{p}<0.05, * * \mathbf{p}<0.01$ ). Reported statistics refer to the comparison between admission and discharge in the patients' group

\begin{tabular}{|c|c|c|c|c|c|}
\hline \multicolumn{2}{|c|}{ Performance Index } & \multicolumn{4}{|c|}{ Contralateral movement } \\
\hline & & Admission & Discharge & $p$ & Healthy Control \\
\hline PI1 & Total time (s) & $4.02 \pm 1.74$ & $3.11 \pm 1.18$ & $0.012^{*}$ & $1.41 \pm 0.72$ \\
\hline $\mathrm{Pl} 2$ & Total smoothness & $4.19 \pm 3.17$ & $2.33 \pm 2.76$ & $0.004 * *$ & $0.19 \pm 0.4$ \\
\hline CCl1 & AD-PD muscles & $1.64 \pm 0.93$ & $2.49 \pm 1.94$ & $0.05^{*}$ & $7.17 \pm 2.99$ \\
\hline $\mathrm{CCl} 2$ & TB-BP muscles & $1.50 \pm 0.77$ & $1.41 \pm 1.02$ & 0.91 & $0.45 \pm 0.27$ \\
\hline \multirow{2}{*}{\multicolumn{2}{|c|}{ Performance Index }} & \multicolumn{4}{|c|}{ Central movement } \\
\hline & & Admission & Discharge & $p$ & Healthy Control \\
\hline PI1 & Total time (s) & $4.10 \pm 2.10$ & $3.07 \pm 1.08$ & $0.007 * *$ & $1.32 \pm 0.72$ \\
\hline $\mathrm{Pl} 2$ & Total smoothness & $5.15 \pm 4.76$ & $2.74 \pm 2.30$ & $0.006^{* *}$ & $0.24 \pm 0.54$ \\
\hline $\mathrm{CCl} 1$ & AD-PD muscles & $2.24 \pm 0.80$ & $3.08 \pm 2.21$ & $0.03 *$ & $7.9 \pm 2.92$ \\
\hline $\mathrm{CCl} 2$ & TB-BP muscles & $1.39 \pm 0.84$ & $1.37 \pm 0.87$ & 0.84 & $0.41 \pm 0.29$ \\
\hline \multirow{2}{*}{\multicolumn{2}{|c|}{ Performance Index }} & \multicolumn{4}{|c|}{ Ipsilateral movement } \\
\hline & & Admission & Discharge & $p$ & Healthy Control \\
\hline PI1 & Total time (s) & $5.25 \pm 2.84$ & $3.15 \pm 1.14$ & $0.0004^{* *}$ & $1.64 \pm 1.04$ \\
\hline $\mathrm{Pl} 2$ & Total smoothness & $7.00 \pm 6.69$ & $2.63 \pm 2.56$ & $0.001 * *$ & $0.62 \pm 0.74$ \\
\hline $\mathrm{CCl} 1$ & AD-PD muscles & $1.24 \pm 0.64$ & $1.89 \pm 1.41$ & $0.02^{*}$ & $4.87 \pm 2.75$ \\
\hline $\mathrm{CCl} 2$ & TB-BP muscles & $1.31 \pm 0.95$ & $1.36 \pm 1.22$ & 0.81 & $0.46 \pm 0.32$ \\
\hline
\end{tabular}

\section{Interjoint Coordination}

The diagram in Figure 10 shows elbow vs. shoulder angles during the outward phase of movement of one patient (n. 7) compared with the same movement performed by one healthy subject of the control group during three repetitions of reaching a target in the contralateral space.

From the diagram, it appears that the movement execution in terms of shoulder-elbow angles, is not significantly affected by the training and different from the execution of the healthy subject. It is interesting to compare the performance in the case of the reach of a central target (Figure 11). Again in the healthy volunteer we can notice a strong correlation between shoulder-elbow angles, while the patient presents a more segmented diagram with lower correlation values.

The difference in interjoint coordination between the executions of contralateral and central reaching, measured in terms of correlation coefficients, is graphically reported in Figure 12, panel A, for all patients and for the healthy control group.

In the reach of a contralateral target the correlation coefficient is almost equal to $-1(-1.00 \pm 0.00)$ in the control group, and appears to be well preserved in the patient's group both before $(-0.89 \pm 0.11)$ and after $(-0.91 \pm 0.09)$ training with no statistically significant effect of the training $(\mathrm{p}=0.27)$. In the case of reach to a central target, the movement executed in the healthy control group presents a high correlation coefficient
$(-0.94 \pm 0.14)$ between elbow and shoulder angles, while in the patient's group we observe a significant increase of the correlation coefficient, from $-0.42 \pm 0.51$ to $-0.69 \pm 0.39(\mathrm{p}<0.0004)$.

The analysis of the same movement executed towards an ipsilateral target cannot be performed in terms of correlation between shoulder and elbow angles. This is because, as it is visible in Figure 13, the movement is performed mainly with single joint movements of shoulder and elbow joints. The main qualitative difference that we notice in the performance after stroke is the reduced involvement of the elbow joint in movement execution.

The effects of training can be measured in terms of maximum elbow $\left(\Delta \alpha_{E L B}\right)$ to shoulder $\left(\Delta \alpha_{S H}\right)$ excursion. As reported in Figure 12, panel B, we did not observe any change of this index before $(4.01 \pm 2.59)$ and after training $(4.4 \pm 2.96)$, while higher values were attained in the healthy control group $(11.48 \pm 8.89)$, denoting a different motion strategy with higher recruitment of elbow joint in reaching directed to ipsilateral targets.

\section{Discussion}

The recovery of motor capabilities during the chronic phase of impairment after stroke with a rehabilitation treatment is documented in literature $[14,15,35]$.

Within the group of patients that participated to this study, we observed coherently with previous research an increase in the FMA and reduction in the MA scores, 


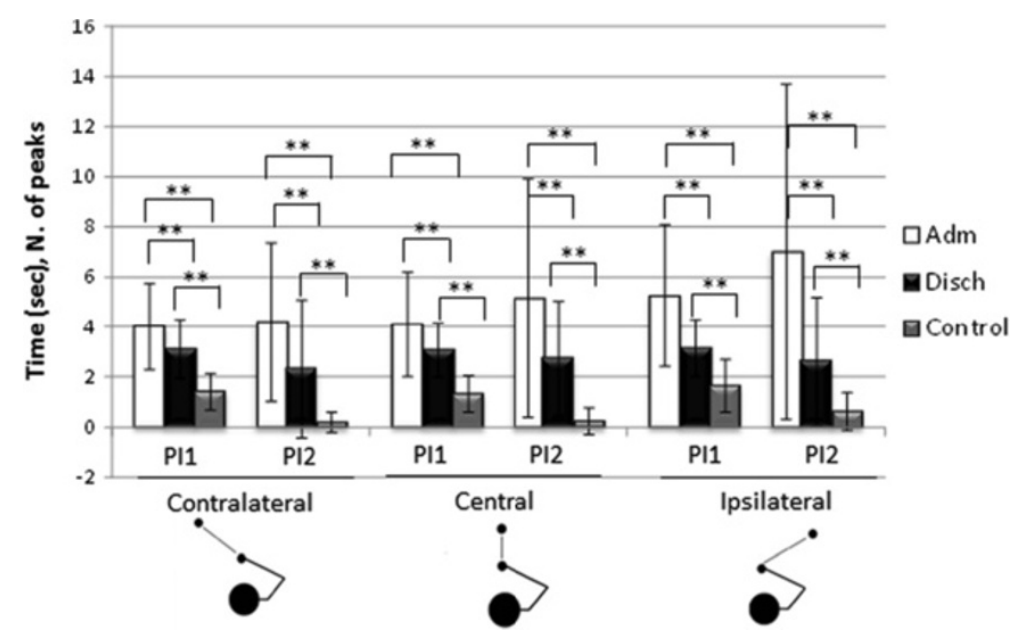

Figure 7 Graphical representation of kinesiologic indexes PI1 (total time) and PI2 (smoothness) changes before and after training (* $\mathrm{p}<0.05,{ }^{* *} \mathrm{p}<0.01$ ).

the former corresponding to an improvement of the motor performance, the latter in a reduction of the muscular spasticity.

In addition, the instrumental study of the reaching performance showed that robotic training produced positive effects in movement execution, in terms of decreased execution time, improved movement smoothness and increased active joint ranges of motion.

Studies of development and recovery from neurological injury strongly suggest that smoothness is a result of learned, coordinative process, rather than a natural consequence of the structure of neuromuscular system [36]. The observed reduction of the movement irregularity indicates a better motor control, i.e. a more appropriate recruitment of agonists and antagonists. Abnormal spatial and temporal patterns of agonist- antagonist muscle activation and inadequate or maladaptive muscle co-activation have been reported in hemiparetic subjects. Abnormal co-activation has been related to diminished agonist motor unit recruitment, impaired antagonist inhibition or both [37] or to a decrease in the number of possible coordinative muscle synergies [38]. Several sources can explain muscle weakness observed after stroke: failure of voluntary motor neuron activation [39], loss of functioning motor units, changes in the properties of the remaining units, inappropriate spatial and temporal patterns of muscle activation, muscle fibre atrophy and contracture.

In our study, the observed functional changes were found to be associated to an improvement in the cocontraction index of proximal joints, in particular for shoulder extension and flexion (CII1 AD/PD), while no changes were observed in the co-contraction ratio of distal joints, i.e. elbow (CII2 TB/BB). From the comparison with data collected in the healthy group, it is evident that a co-activation of biceps and triceps muscle groups persists in the patient group, mainly due to the biceps activation to contrast the weight of the forearm during movement execution. On the contrary, the improved CII1 appears to be associated to the specific performed training exercises.

The decrease in motion range after stroke may be also a direct consequence of an enlarged antagonist muscle activity, due to the loss of ability to relax muscles not involved in the voluntary effort[40], accompanied by an increased resistance to movement [41]. This may be due to a decrease in the stretch- reflex threshold $[31,42]$ and to limitations in its central regulation $[43,44]$.

Additionally, there is evidence that the segmented nature of stroke patients' arm movement can be attributed to a deficit in interjoint coordination [8]. In our group of patients, we observed an increase of interjoint coordination of shoulder and elbow joints for reaching movements directed towards a central target and differences in the changes of functional performance, dependent of the spatial position of the target to be reached, i.e. contralateral vs. ipsilateral targets. These experimental evidences might be explained taking into account the redundancy of the muscoskeletal system. For instance some movements, such as reaching an ipsilateral target,

Table 4 Pearson correlation coefficients for correlation of PI1-2 (central target) vs. FMA and MA clinical scores (* $\left.\mathbf{p}<0.05,{ }^{* *} \mathbf{p}<0.01\right)$

\begin{tabular}{llll}
\hline & & PI1 & PI2 \\
\hline FMA & $R$ & $-.501^{*}$ & $-.589^{*}$ \\
& $P$ & .034 & $\mathbf{. 0 1 0}$ \\
MA & $R$ & .427 & $\mathbf{. 5 3 0 ^ { * }}$ \\
& $P$ & .077 & $\mathbf{. 0 0 2 4}$ \\
\hline
\end{tabular}




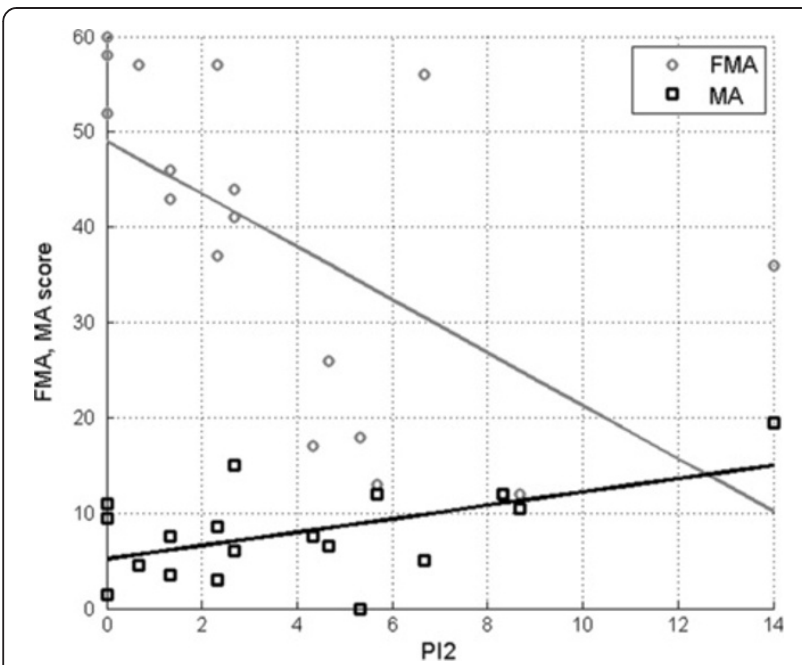

Figure 8 Correlation of FMA and MA score with index PI2 (smoothness index to reach a central target).

can be executed by choosing among different available motor strategies, selecting appropriate interjoint coordination and desired trajectory [45].

Hemiparetic patients normally exhibit abnormal joint coupling between shoulder and elbow joints [46] and loss of independent joint control. According to some theories $[45,47,48]$, even if the issue is still controversial, recovery of movements from stroke in the upper extremity begins with the development of a flexor synergy (shoulder abductionelbow flexion) followed by an extensor synergy (shoulder adduction- elbow extension) pattern [49], while isolated joint movements remain still compromised. This may result into the disruption of movement in terms of the required interjoint coordination.

The kinesiologic data from our study (Table 3) show that upper limb inward movements, usually performed within the "flexion synergy", were more easily preserved in patients and less affected by the robotic training, if compared to outward movements. But the same finding can also be explained in terms of the higher involvement of shoulder extensor muscles in the outward phase, required for the antigravity support of the arm.

Similarly, despite the overall improvement of the kinesiologic parameters in the different conditions of free limb reaching task, we observed that the movement time (PI1a) and the smoothness (PI2a) of the outward movement into the contralateral space did not improve with training as much as in the ipsilateral space.

This aspect might be explained by analysing the main features of the performed movements in terms of interjoint coordination. It seems that the coordination pattern of shoulder and elbow joints is better preserved for reaching movements executed in the contralateral space, where we did not observe changes in the correlation factor between shoulder and elbow angles. This can be explained in terms of the "extensor synergy" required for, with a combined involvement of shoulder adduction and elbow extension [45].

It has been shown that the gravity compensation reducing the involuntary coupling between shoulder abduction and elbow flexion (flexor synergy) results then in a larger elbow extension during planar reach tasks [50,51]. In our group of patients, we did not observe neither change of the co-contraction index associated to elbow function (CII2 $\mathrm{BB} / \mathrm{TB}$ ) nor changes in the elbow to shoulder angles ratio in the execution of movement to ipsilateral targets. The training was mostly effective in terms of movement execution involving shoulder flexion/extension, even if single joint improvements were observed also in terms of active ranges of motion for shoulder abduction and elbow flexion/extension.

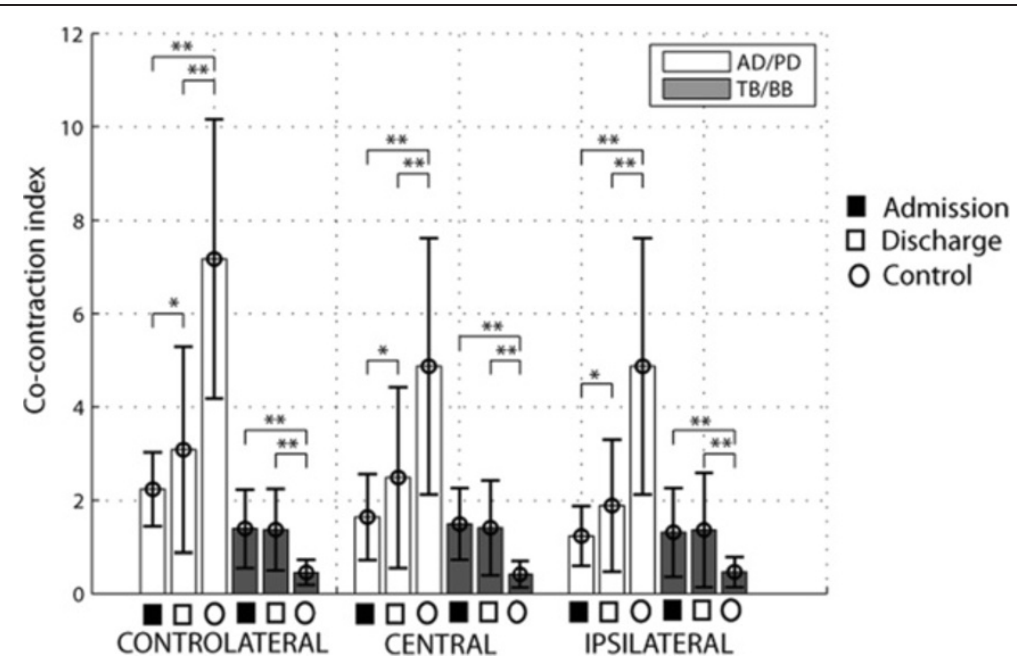

Figure 9 Co-contraction ratio for different couples of agonist/antagonist muscle, pre and after training $(* p<0.05)$. 
Table 5 Comparison of outward vs. inward movement performance

\begin{tabular}{|c|c|c|c|c|c|c|c|c|c|c|}
\hline \multicolumn{2}{|c|}{ Performance Index } & \multicolumn{3}{|c|}{ Contralateral movement } & \multicolumn{3}{|c|}{ Central movement } & \multicolumn{3}{|c|}{ Ipsilateral movement } \\
\hline & & Admission & Discharge & $\mathbf{p}$ & Admission & Discharge & $p$ & Admission & Discharge & $p$ \\
\hline $1 \mathrm{~d}$ & Outward time (s) & $1.30 \pm 0.57$ & $1.10 \pm 0.60$ & 0.172 & $1.26 \pm 0.69$ & $0.93 \pm 0.35$ & $0.015 *$ & $1.38 \pm 0.71$ & $0.99 \pm 0.54$ & $0.008^{* *}$ \\
\hline $511 \mathrm{~b}$ & Inward time (s) & $1.40 \pm 1.15$ & $1.13 \pm 0.52$ & 0.124 & $1.33 \pm 0.72$ & $1.22 \pm 0.57$ & 0.483 & $2.07 \pm 1.84$ & $1.09 \pm 0.27$ & $0.014^{*}$ \\
\hline 12 a & Outward smoothness & $1.22 \pm 1.31$ & $0.81 \pm 1.64$ & 0.170 & $1.19 \pm 1.36$ & $0.59 \pm 0.69$ & $0.030^{*}$ & $1.44 \pm 1.40$ & $0.56 \pm 1.01$ & $0.003 * *$ \\
\hline 12 b & Inward smoothness & $1.33 \pm 1.80$ & $0.67 \pm 0.78$ & $0.034^{*}$ & $1.48 \pm 1.70$ & $1.22 \pm 1.31$ & 0.483 & $2.70 \pm 3.94$ & $0.85 \pm 0.91$ & $0.030 *$ \\
\hline
\end{tabular}

The study of kinematic changes is needed to better understand the observed improvements in motor performance [52,53], because the measurements at a functional level cannot differentiate between improvements at the motor recovery level or due to alternative compensatory strategies.

In this study we observed that the rehabilitation training, conducted on multi-joint and spatial reaching movements, can lead to significant improvements in the kinesiologic indexes related to the performance execution and motion smoothness, indicating a carry-over of the observed improvements during training into improved function.

Moreover the observed correlation of some kinesiologic parameters, such as the index of smoothness, with the clinical assessment, supports the development in

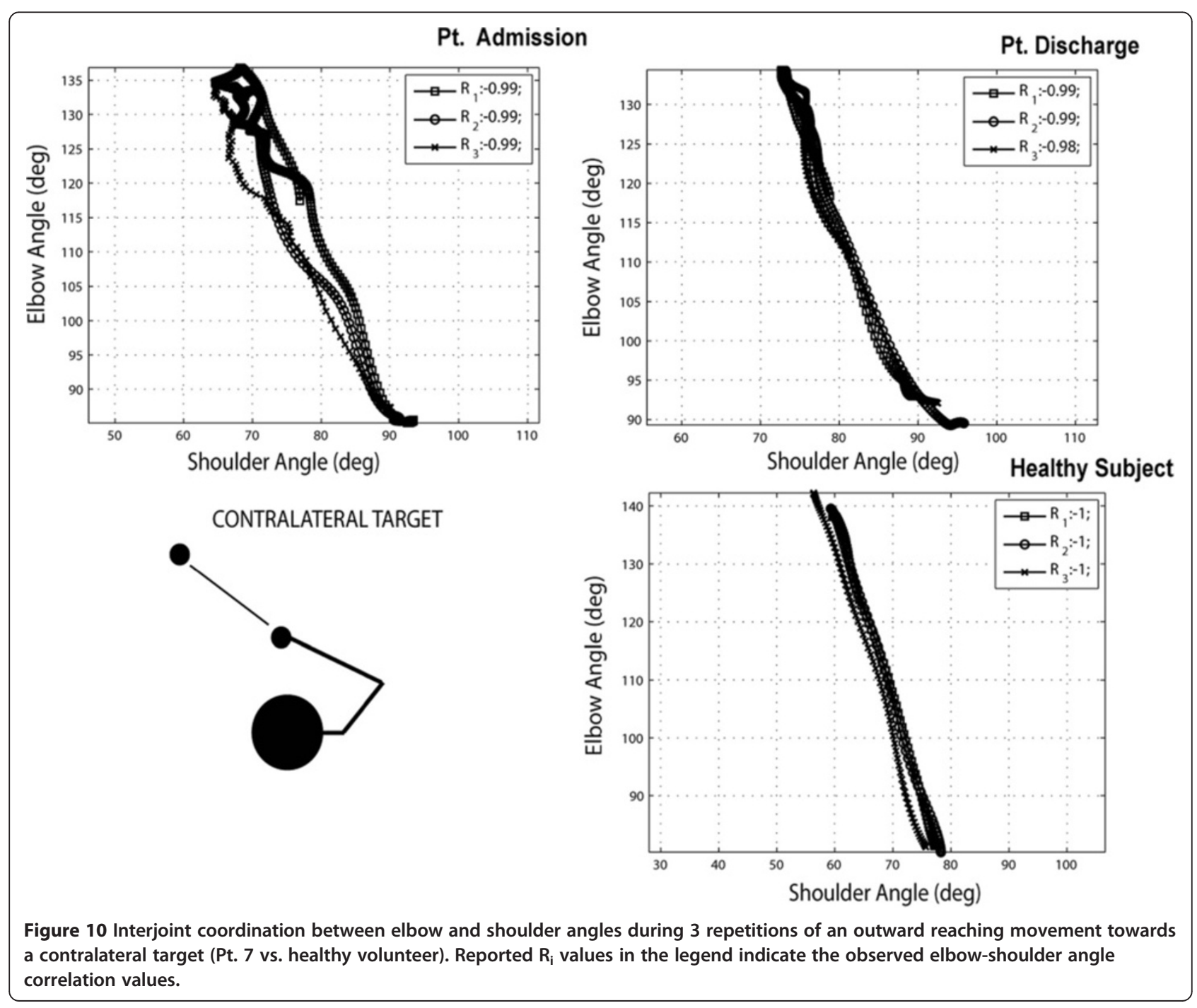




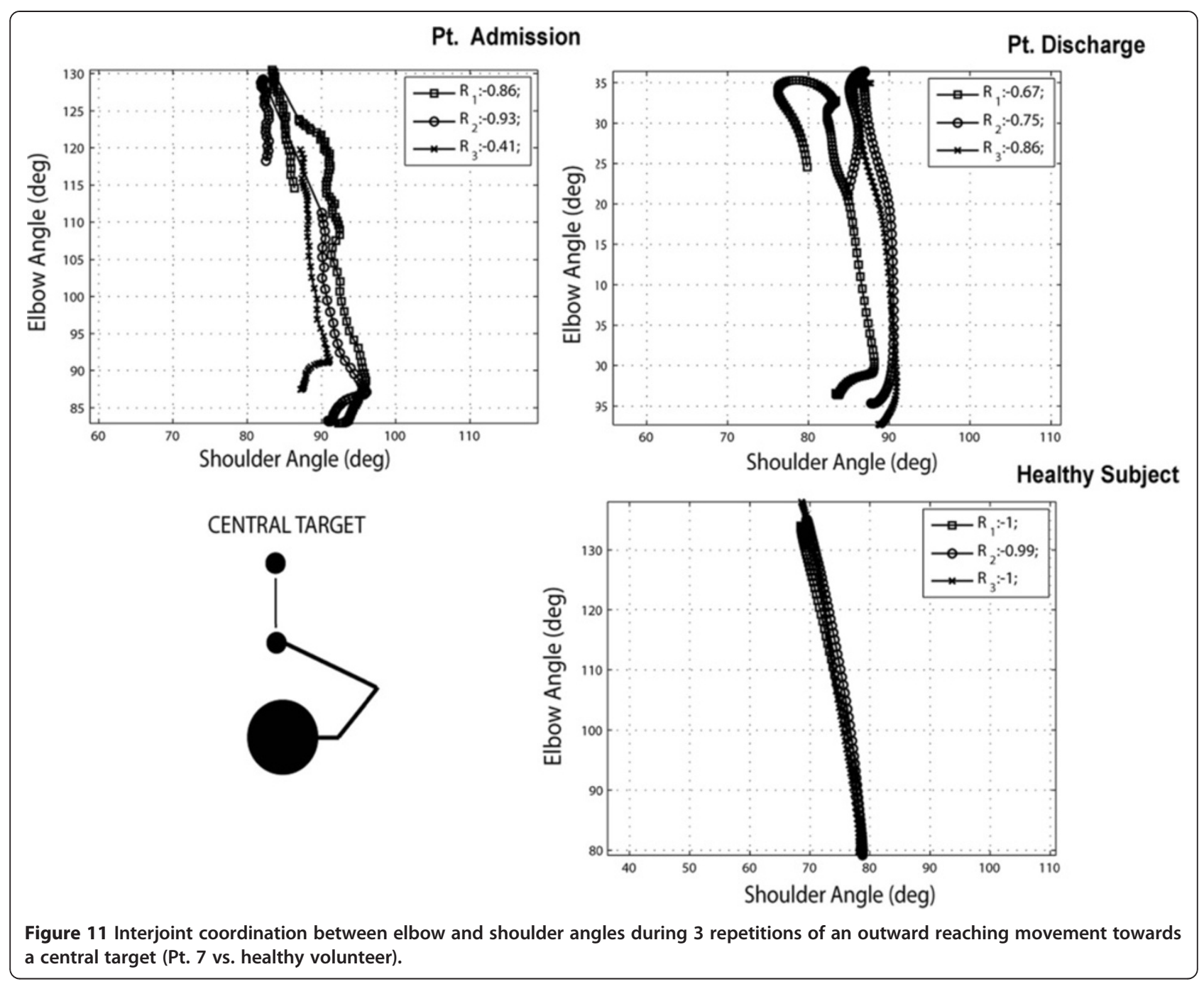

robotic assisted rehabilitation of new methods for automatic assessment of patient's performance, conducted continuously all over the training.
These changes were reflected also in a better interjoint coordination of shoulder and elbow joints, that probably contributes to the overall improvement of quality of
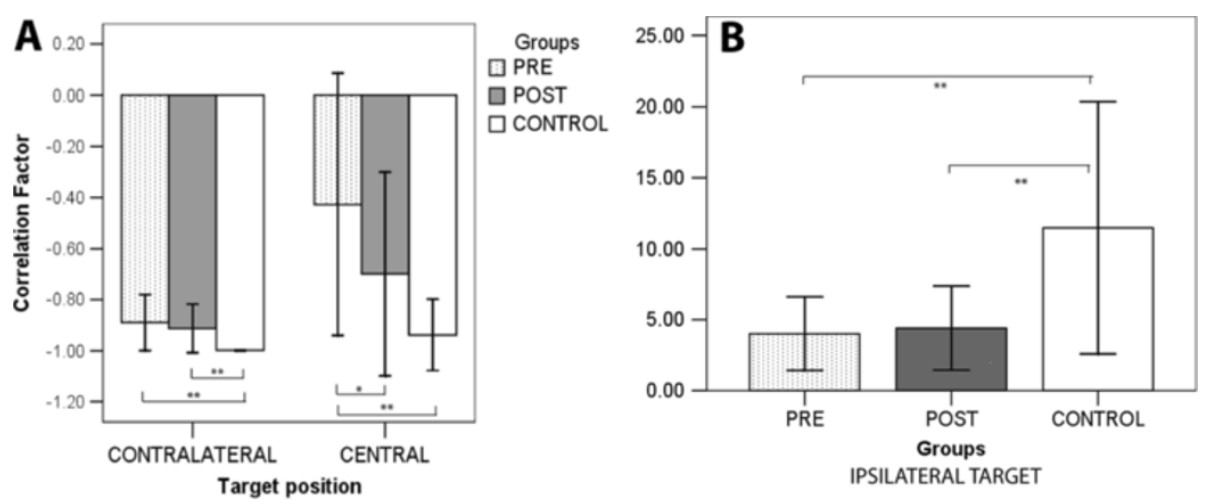

Figure 12 Interjoint correlation coefficients before and after training according to target location for central and contralateral targets. 


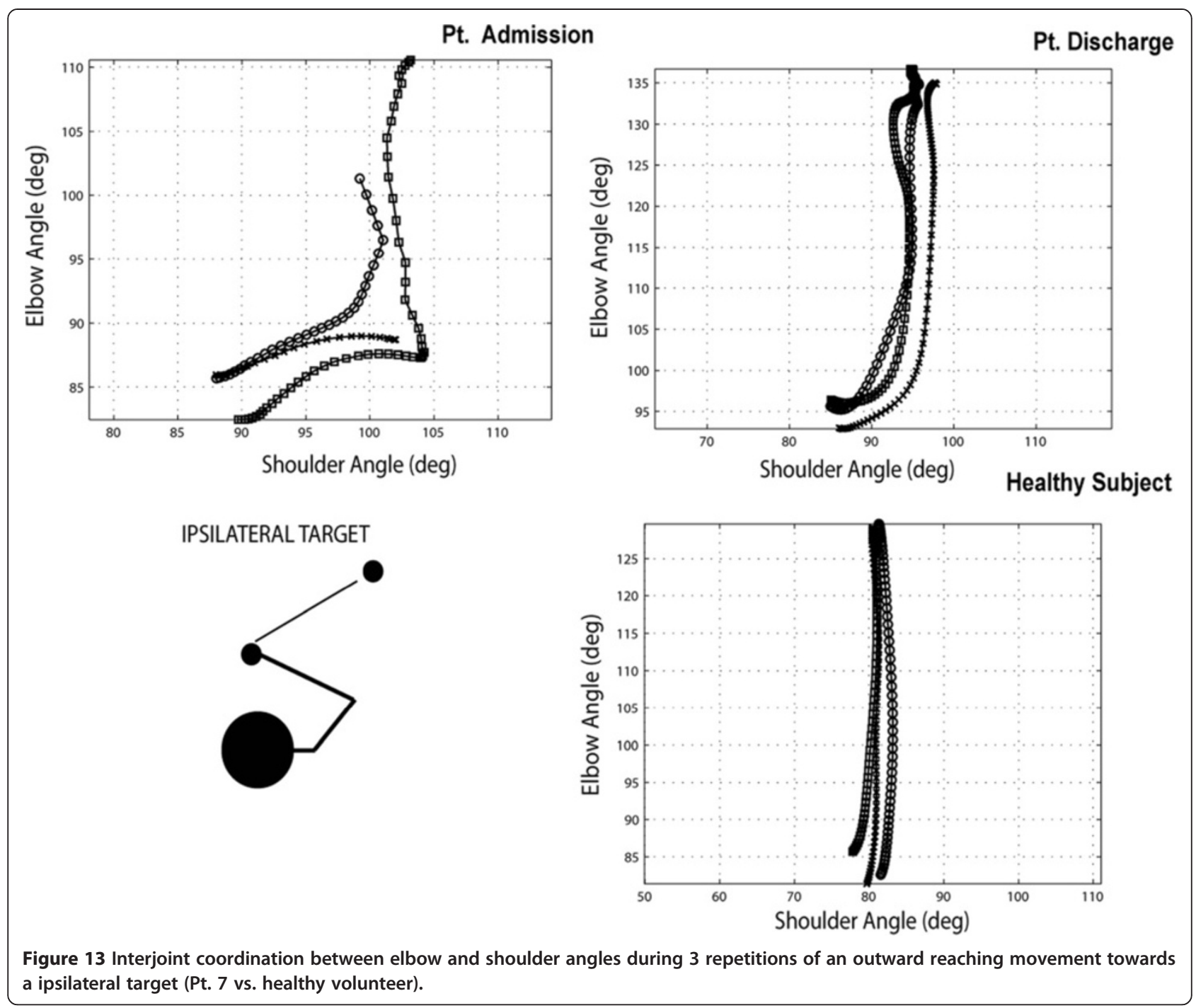

movement, and better ability to execute single joint and out of synergy movements.

The analysis of kinesiologic performance in relation to the changes in the EMG pattern of agonist- antagonist muscle co-activation showed an improvement of the cocontraction index for shoulder flexion- extension, indicating a better expression of selective activation of agonist and antagonist muscles, and underlining the possible presence of plastic phenomena even in a long time (some years) from the event.

This study points out the importance of conducting the rehabilitation training of upper-limb after stroke with multi-joint and 3D spatial movements. In future works, the role of interjoint coordination and muscle recruitment in the recovery of movement from stroke and in the regained ability to explore different portions of the peri-personal space needs to be further investigated.

\section{Competing interest}

The authors declare that they have no competing interests.

\section{Acknowledgements}

The authors wish to acknowledge the contribution from Alberto Montagner, Luigi Borelli and Giovanni Greco, for their support in the management of the clinical protocol and data analysis, and to Giuseppe Lamola, Martina Venturi, Edoardo Sotgiu and Claudio Loconsole for the data acquisition in the healthy control group. This research was supported by a financial contribution of Fondazione Monte Paschi Siena, Italy, by the Integrated Project SKILLS "Multimodal Interfaces for capturing and Transfer of Skills" and by the Integrated Project BEAMING "Beaming through augmented media for natural networked gatherings", funded by the European Commission.

\section{Author details}

${ }^{1}$ PERCRO (Perceptual Robotics) Laboratory, Scuola Superiore Sant'Anna, Viale Rinaldo Piaggio, 34, 56025Pontedera, Pisa, Italy. ${ }^{2}$ Neurorehabilitation Unit, Department of Neurosciences, Azienda Ospedaliera Universitaria Pisana, Via Paradisa, 2, 56124, Pisa, Italy.

\section{Authors' contribution}

AF designed the study, managed the robotic and VR system design and implementation, supervised the robotic training, conducted the data 
analysis and interpretation of results, drafted the manuscript. CP participated to the robotic training with patients and to the clinical evaluation, contributed to the ideation of training exercises and to the organization of the training sessions. CC contributed to the medical supervision of the robotic training and to the recruitment and kinesiologic evaluation of the control group. IC was in charge of the clinical assessment of patients and conduction of kinesiologic tests. LB contributed to the data analysis and interpretation of results. MB contributed to the robotic and VR system design and implementation. BR was responsible for the clinical protocol, and supervised the clinical trial. MCC designed the study, was responsible for patients' enrollment, conduction of clinical trial and medical supervision of the robotic training, contributed to the data analysis and drafted the manuscript. All authors read and approved the final manuscript.

Received: 08 September 2011 Accepted: 09 June 2012 Published: 09 June 2012

\section{References}

1. Carod-Artal J, Egido JA, Gonzalez JL, Varela de Seijas E: Quality of life among stroke survivors evaluated 1 year after stroke: experience of a stroke unit. Stroke 2000, 31(12):2995-3000.

2. Clarke P, Marshall V, Black SE, Colantonio A: Well-being after stroke in Canadian seniors: findings from the Canadian Study of Health and Aging. Stroke 2002, 33(4):1016-1021.

3. Nakayama H, Jorgensen HS, Raaschou HO, Olsen TS: Recovery of upper extremity function in stroke patients: the Copenhagen Stroke Study. Arch Phys Med Rehabil 1994, 75(4):394-398.

4. Bourbonnais $D$, Vanden Noven $S$ : Weakness in patients with hemiparesis. Am J Occup Ther 1989, 43(5):313-319.

5. Ryerson S, Levit K: In Physical therapy of the shoulder. Edited by Donatelli R. New York: Churchill Livingstone; 1987.

6. Carr JH, Shepherd RB: Movement science: foundations for physical therapy in rehabilitation. In A motor learning model for rehabilitation, Volume xiii. 2nd edition. Gaithersburg: Aspen Publishers; 2000:220.

7. Archambault P, Pigeon P, Feldman AG, Levin MF: Recruitment and sequencing of different degrees of freedom during pointing movements involving the trunk in healthy and hemiparetic subjects. Exp Brain Res 1999, 126(1):55-67.

8. Levin MF: Interjoint coordination during pointing movements is disrupted in spastic hemiparesis. Brain 1996, 119(1):281-293.

9. Carr JH, Shepherd RB: The upper motor neuron syndrome in "Neurological rehabilitation: optimizing motor performance". Edinburgh; New York: Churchill Livingstone; 2010:193-215.

10. Teasell RW, Kalra L: What's new in stroke rehabilitation. Stroke 2004, 35 (2):383-385

11. Barreca S, Wolf SL, Fasoli S, Bohannon R: Treatment interventions for the paretic upper limb of stroke survivors: a critical review. Neurorehabil Neural Repair 2003, 17(4):220-226.

12. Feys HM, De Weerdt WJ, Selz BE, Cox Steck GA, Spichiger R, Vereeck LE, Putman KD, Van Hoydonck GA: Effect of a therapeutic intervention for the hemiplegic upper limb in the acute phase after stroke: a single-blind, randomized, controlled multicenter trial. Stroke 1998, 29(4):785-792.

13. Kwakkel G, Wagenaar RC, Twisk JW, Lankhorst GJ, Koetsier JC: Intensity of leg and arm training after primary middle-cerebral-artery stroke: a randomised trial. Lancet 1999, 354(9174):191-196.

14. Michaelsen SM, Levin MF: Short-term effects of practice with trunk restraint on reaching movements in patients with chronic stroke. A controlled trial. Stroke 2004, 35:1914-1919.

15. Takahashi CD, Der-Yeghiaian L, Le V, Motiwala RR, Cramer SC: Robot-based hand motor therapy after stroke. Brain 2008, 131(2):425-437.

16. Prange GB, Jannink MJ, Groothuis-Oudshoorn CG, Hermens HJ, ljzerman MJ: Systematic review of the effect of robot-aided therapy on recovery of the hemiparetic arm after stroke. J Rehabil Res Dev 2006, 43(2):171-84.

17. Kwakkel G, Kollen B, Lindeman E: Understanding the pattern of functional recovery after stroke: facts and theories. Restor Neurol Neurosci 2004, 22 $(3-5): 281-299$.

18. Timmermans AA, Seelen HA, Willmann RD, Kingma H: Technology-assisted training of arm-hand skills in stroke: concepts on reacquisition of motor control and therapist guidelines for rehabilitation technology design. $J$ Neuroeng Rehabil 2009, 6:1-18.
19. Sveistrup H: Motor rehabilitation using virtual reality. J NeuroEng Rehabil 2004, 1(1):10.

20. Jang SH, Ahn SH, Yang DS, Lee DK, Kim DK, Son SM: Cortical reorganization of hand motor function to primary sensory cortex in hemiplegic patients with a primary motor cortex infarct. Arch Phys Med Rehabil 2005, 86(8):1706-1708.

21. Ferraro M, Palazzolo JJ, Krol J, Krebs HI, Hogan N, Volpe BT: Robot-aided sensorimotor arm training improves outcome in patients with chronic stroke. Neurology 2003, 61(11):1604

22. Sukal TM, Ellis MD, Dewald JPA: Shoulder abduction-induced reductions in reaching work area following hemiparetic stroke: neuroscientific implications. Exp Brain Res 2007, 183(2):215-223.

23. Krebs $\mathrm{HI}$, Ferraro M, Buerger SP, Newbery MJ, Makiyama A, Sandmann M, Lynch D, Volpe BT, Hogan N: Rehabilitation robotics: pilot trial of a spatial extension for MIT-Manus. J NeuroEng Rehabil 2004, 1(1):5.

24. Sanchez RJ, Liu J, Rao S, Shah P, Smith R, Rahman T, Cramer SC, Bobrow $J E$, Reinkensmeyer DJ: Automating arm movement training following severe stroke: functional exercises with quantitative feedback in a gravity-reduced environment. Neural Syst Rehabil Eng IEEE Trans 2006, 3:378-389.

25. Frisoli A, Salsedo F, Bergamasco M, Rossi B, Carboncini MC: A forcefeedback exoskeleton for upper-limb rehabilitation in virtual reality. Appl Bionics Biomech 2009, 6(2):115-126.

26. Frisoli A, Rocchi F, Marcheschi S, Dettori A, Salsedo F, Bergamasco M: A new force- feedback arm exoskeleton for haptic interaction in virtual environments. In First Joint Eurohaptics Conference and Symposium on Haptic Interfaces for Virtual Environment and Teleoperator Systems. Pisa: IEEE; 2005.

27. Frisoli A, Borelli L, Montagner A, Marcheschi S, Procopio C, Salsedo F, Bergamasco M, Carboncini M, Tolaini M, Rossi B: Arm rehabilitation with a robotic exoskeleleton in Virtual Reality. In IEEE ICORR, 10th International Conference on Rehabilitation Robotics. Noordwijk: IEEE; 2007.

28. Fugl-Meyer AR, Jaasko L, Leyman I, Olsson S, Steglind S: The post-stroke hemiplegic patient. A method for evaluation of physical performance. $J$ Rehabil Med 1975, 7(1):13-31.

29. Bohannon RW, Smith MB: Interrater reliability of a modified ashworth scale of muscle spasticity. Phys Ther 1987, 67(2):206-207.

30. Hermens HJ, Freriks B, Merletti R, Hägg G, Stegeman D, Blok J, et al: In European recommendations for surface electromyography: results of the SENIAM project. Edited by Enschede N. The Netherlands: Roessingh Research and Development; 1999.

31. Feldman RG, Young RR, Koella WP: Spasticity: disordered motor control. Miama: Symposia Specialists; 1980:510

32. Montagner A, Frisoli A, Borelli L, Procopio C, Bergamasco M, Carboncini MC, Rossi B: A pilot clinical study on robotic assisted rehabilitation in VR with an arm exoskeleton device. In IEEE Virtual Rehabilitation. Venice: IEEE; 2007.

33. Reinkensmeyer DJ, Kahn LE, Averbuch M, McKenna-Cole A, Schmit BD, Rymer WZ: Understanding and treating arm movement impairment after chronic brain injury: progress with the ARM guide. J Rehabil Res Dev 2000, 37(6):653-62.

34. Barker RN, Brauer S, Carson R: Training-induced changes in the pattern of triceps to biceps activation during reaching tasks after chronic and severe stroke. Exp Brain Res 2009, 196(4):483-496.

35. Ruth NB, Sandra B, Richard C: Training-induced changes in the pattern of triceps to biceps activation during reaching tasks after chronic and severe stroke. Exp Brain Res 2009, 196(4):483-496.

36. von Hofsten C: Structuring of early reaching movements: a longitudinal study. J Mot Behav 1991, 23(4):280-92.

37. Hufschmidt A, Mauritz KH: Chronic transformation of muscle in spasticity: a peripheral contribution to increased tone. J Neurol Neurosurg Psychiatry 1985, 48(7):676-685.

38. Tardieu C, Huet de la Tour E, Bret MD, Tardieu G: Muscle hypoextensibility in children with cerebral palsy: I. Clinical and experimental observations. Archives of Physical and Medical. Rehabilitation 1982, 63(3):97-102.

39. Gracies JM: Pathophysiology of spastic paresis. I: paresis and soft tissue changes. Muscle Nerve 2005, 31(5):535-551.

40. Gracies JM: Pathophysiology of spastic paresis. II: emergence of muscle overactivity. Muscle Nerve 2005, 31(5):552-571.

41. Levin MF: Sensorimotor deficits in patients with nervous system lesions: explanations based on the model of motor control. Hum Mov Sci 2000, 19:107-137. 
42. Levin MF, Selles RW, Verheul MH, Meijer OG: Deficits in the coordination of agonist and antagonist muscles in stroke patients: implications for normal motor control. Brain Res 2000, 853(2):352-369.

43. Katz RT, Rymer WZ: Spastic hypertonia: mechanisms and measurement. Arch Phys Med Rehabil 1989, 70(2):144-55.

44. Powers RK, Campbell DL, Rymer WZ: Stretch reflex dynamics in spastic elbow flexor muscles. Ann Neurol 1989, 25(1):32-42.

45. Cirstea M, Levin MF: Compensatory strategies for reaching in stroke. Brain 2000, 123(5):940.

46. Brunnstrom S: Movement therapy in hemiplegia; a neurophysiological approach. New York: Harper \& Row; 1970:192.

47. Yao J, Chen A, Carmona C, Dewald J: Cortical overlap of joint representations contributes to the loss of independent joint control following stroke. Neurolmage 2009, 45(2):490-499.

48. Dipietro L, Krebs HI, Fasoli SE, Volpe BT, Stein J, Bever C, Hogan N: Changing motor synergies in chronic stroke. J Neurophysiol 2007, 98 (2):757.

49. Cuccurullo SJ: Physical medicine and rehabilitation board review.: Demos Medical Publishing; 2004

50. Beer RF, Given JD, Dewald JPA: Task-dependent weakness at the elbow in patients with hemiparesis. Arch Phys Med Rehabil 1999, 80(7):766-772.

51. Beer R, Dewald JA, Dawson M, Rymer WZ: Target-dependent differences between free and constrained arm movements in chronic hemiparesis. Exp Brain Res 2004, 156(4):458-470.

52. Rohrer B, Fasoli S, Krebs HI, Hughes R, Volpe B, Frontera WR, Stein J, Hogan $\mathrm{N}$ : Movement smoothness changes during stroke recovery. J Neurosci 2002, 22(18):8297-8304.

53. Kahn L, Zygman M, Rymer WZ, Reinkensmeyer D: Robot-assisted reaching exercise promotes arm movement recovery in chronic hemiparetic stroke: a randomized controlled pilot study. J NeuroEng Rehabil 2006, 3 (1):1-13.

doi:10.1186/1743-0003-9-36

Cite this article as: Frisoli et al:: Positive effects of robotic exoskeleton training of upper limb reaching movements after stroke. Journal of NeuroEngineering and Rehabilitation 2012 9:36. 